016 WINNER OR LOSER: A SCOPING STUDY ON THE IMPLEMENTATION OF TRADE IN HEALTH SERVICES IN THE PHILIPPINES

Maria Soledad Q Antonio. Centre for Environment and Population Health, Griffith University, Brisbane, Australia

\title{
10.1136/bmjopen-2015-forum2015abstracts. 16
}

Background The Philippines has been trading its health services already to foreigners, little is known about the magnitude of its implementation and the domestic regulations to manage its benefits and consequences.

Objectives To determine what is known and unknown about the Philippine trade in health services, specifically the services sought by foreigners in the Philippines.

Methods A comprehensive literature review of published peerreviewed journals and gray literature was done and was accomplished in the following steps: (1) identifying the question and relevant literature; (2) selecting the literature; (3) collating into themes using NVIVO 10 software. Different themes were identified from this process.

Result There were 124 articles from the database searched, the majority of which were peer-reviewed journals and 54 more articles were included after hand searching relevant websites with a total of 178 articles identified. Abstracts were inspected and 101 relevant full papers were included in the review. The themes identified in the review were based on the World Trade Organization General Agreement on Trade in Services (WTO GATS) definition and they were the following: (1) Cross border supply (e.g. US availing the health services of medical transcriptionists in the Philippines); (2) Consumption abroad (e.g. foreigners availing health services in the Philippines); (3) Foreign direct investment (e.g. foreigners investing in the hospitals or retirement villages in the Philippines); (4) Natural persons (e.g. Filipino nurses providing health services in hospitals abroad); (5) Philippine domestic regulations on trade in health services. These themes were the most discussed issues on trade in health services in the Philippines.

Conclusion This review shows research and policy gaps in the trade in the Philippine health services specifically on WTO GATS consumption abroad, where foreigners avail the health services in the Philippines. In the absence of a comprehensive Philippine domestic regulation on trade in health services to protect the Filipino people, there was documented exploitation among the poor and vulnerable Filipinos motivated into commercial surrogacy and brokered commercial organ transplant. What was seen in this article and the policy gaps it revealed is a huge potential for contribution in the future to understand trade in health services and how it could be implemented in the Philippines. 